\title{
Comparison Study on Body Shape of Li and Han Nationality Students in China

\author{
JiJin Sun ${ }^{1, a,{ }^{*}}$, Yan Sheng ${ }^{1, a}$
} \\ ${ }^{1}$ Qiongtai teachers college, haikou,China \\ asjj2002033@163.com
}

Keywords: Body; Fitness; Health; Li nationality; P.E

\begin{abstract}
To study the body shape status of 7-12 years old Li nationality students of China,with a comparison in body shape between Li nationality and national Han nationality students of China, select the average level of 7-12 years students' body shape as the comparative object, the research indexes includes 3 items,such as height,weight,and chest,etc.And the comparison periods is 1985-1995,1985-2000,1985-2005, and 1985-2010,etc. Then find that,from the year 1985, the average of $\mathrm{Li}$ nationality students is lower than Han nationality in height,weight and chest.But in 1985,Li nationality students' level is higher than Han nationality students in height and chest.So the results means in 30years, Li nationality students' level is lower than Han nationality students' in body shape.and the gap is increasing gradually now.Perhaps the social and economic backwardness of $\mathrm{Li}$ nationality is the main reason.So,to improve the societyl and economic development of $\mathrm{Li}$ nationality,and to provide more nutrition to Li nationality students is the better way to reinforce their body structure.
\end{abstract}

\section{Introduction}

Strong fitness is necessary to one's life,and there are many differences in different regions,nationalities, genders,etc.[1]Li nationality is a minority nationality in China,which live in an island,with many remove mountains and forests around them.Li nationality is one of the earlist fitness monitor minority nationalities in China.[2]In 30 years,Li nationality students has many changes in body shape,to compare the changes with Han nationality students will show the differences of development law of fitness between them.

\section{Research objects and methods}

Research objects. The objects include 7-18 years old Li nationality students, which live in Hainan island,the number of pupils is 1200.And the comparison people is Han nationality,the number is 1800.

Research Methods. The main methods about literature,survey,measurement and statistics.

In 2014,a survey about Li nationality students in Wuzhishan and Qiongzhong of Hainan province was finished.The measurement methods comes from "Chinese national student physical health standard" ,and the measurement indexes about height,weight and chest.

In the comparison of data,the main comparison object is average level, which the original data comes from Chinese government's opened reports[3,4,5,6,7].

\section{Results}

Comparison in Changes of Height in Different Periods of Li Nationality Students. Fig .1 shows,Li nationality students's height is always growth in 30 years. From 1985 to 2014,the school boy added his height over $3 \mathrm{~cm}$, and the school girl has the same performance. 


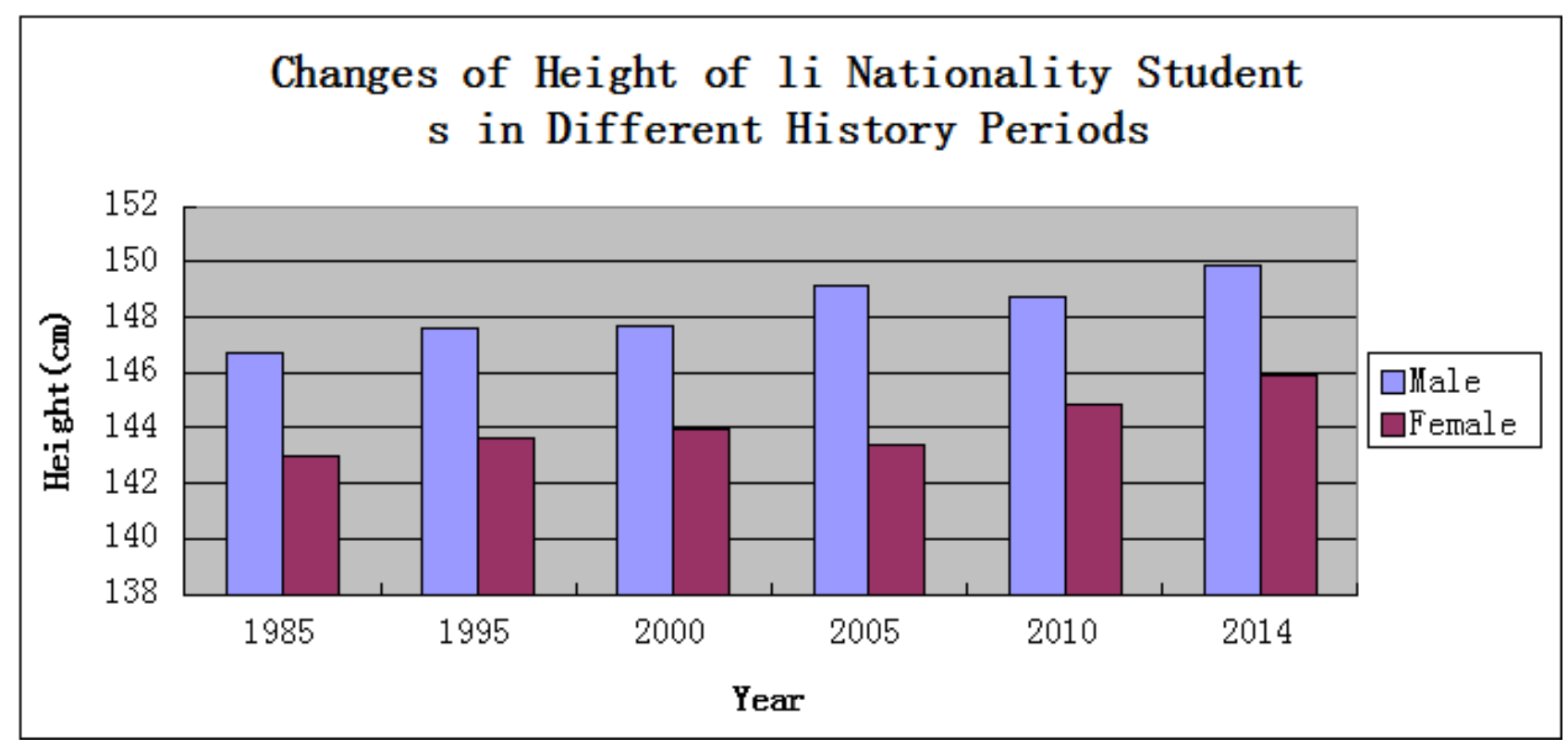

Figure. 1

Comparison in Height of Li and Han Nationality Male Students . The table 1 tells,one hand,in 30 years,Li nationality students is lower in height than national rural students,except for 1985.it means Li nationality students' height has a deep gap with national average level.

The other hand,the gap between Li nationality and national students has a rapid expanding.From the time of 1995 to 2010 , the data is changed from -2.53 to -5.09 .

Table 1 Comparison in height of 7-18 years old $\mathrm{Li}$ and national boys $\quad(\mathrm{cm})$

\begin{tabular}{ccccccc}
\hline \multirow{2}{*}{ Subject } & \multicolumn{6}{c}{ Average } \\
\cline { 2 - 7 } & 1985 & 1995 & 2000 & 2005 & 2010 & 2014 \\
\hline Li nationality school boy & 146.69 & 147.59 & 147.70 & 149.17 & 148.77 & 149.87 \\
National rural school boy & 142.12 & 150.12 & 151.33 & 152.31 & 153.86 & \\
Difference & 4.57 & -2.53 & -3.63 & -3.14 & -5.09 & \\
\hline
\end{tabular}

Comparison in Height of $\mathrm{Li}$ and Han Nationality Female Students . The school girl of Li nationality has a same performance in height.In table 2,the data of Li nationality school girl is lower than national average level.

Table 2 Comparison in height of 7-18 years old Li and national girls $(\mathrm{cm})$

\begin{tabular}{ccccccc}
\hline \multirow{2}{*}{ Subject } & \multicolumn{6}{c}{ Average } \\
\cline { 2 - 7 } & 1985 & 1995 & 2000 & 2005 & 2010 & 2014 \\
\hline Li nationality school girl & 142.98 & 143.65 & 143.93 & 143.43 & 144.85 & 145.90 \\
National rural school girl & 141.48 & 144.32 & 145.25 & 145.93 & 147.05 & \\
Difference & 1.50 & -0.67 & -1.32 & -2.50 & -2.20 \\
\hline
\end{tabular}

Comparison in Changes of Weight in Different Periods of Li Nationality Students. The weight of $\mathrm{Li}$ nationality students is growing rapidly,especially the school boy has a steady growth tendency,and the school girl has a good performance since2014(from Fig .2). 


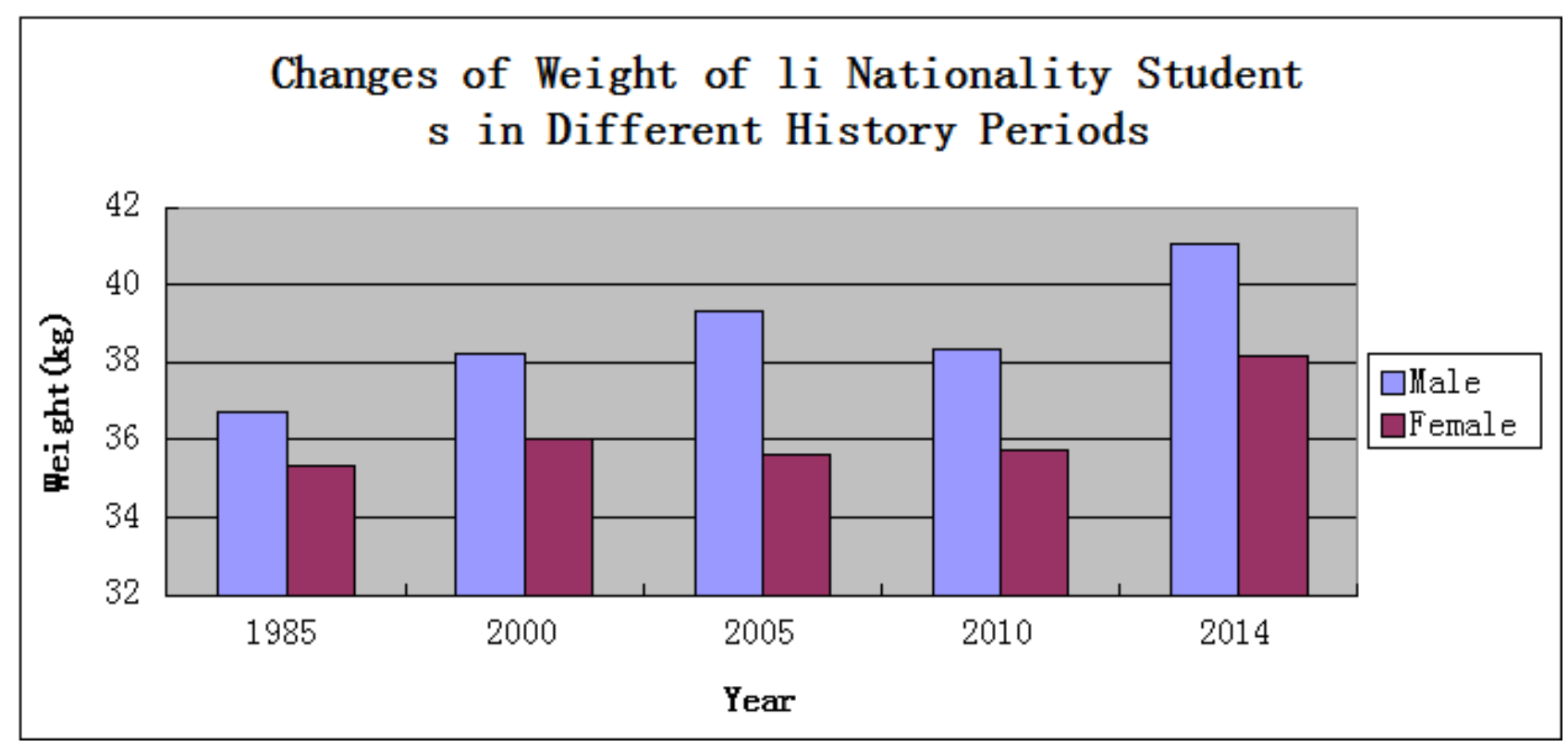

Figure. 2

Comparison in Weight of $\mathrm{Li}$ and Han Nationality Male Students. In weight,the tendency is same to the height.Li nationality school boy's average is lower than nationality rural school boy,and the gap is expanding rapidly( from Table 3 ).

Table 3 Comparison in weight of 7-18 years old $\mathrm{Li}$ and national boys $(\mathrm{kg})$

\begin{tabular}{cccccc}
\hline Subject & \multicolumn{5}{c}{ Average } \\
\cline { 2 - 5 } & 1985 & 2000 & 2005 & 2010 & 2014 \\
\hline Li nationality school boy & 36.69 & 38.21 & 39.34 & 38.32 & 41.05 \\
National rural school boy & 36.91 & 40.38 & 41.70 & 43.72 & \\
Difference & -0.22 & -2.17 & -2.36 & -5.4 & \\
\hline
\end{tabular}

Comparison in Weight of $\mathbf{L i}$ and Han Nationality Female Students. The Li nationality school girl's weight is no competitive advantage than national rural students.it has the same tendency to $\mathrm{Li}$ nationality school boys.in 30 years, the gap is expanding rapidly(from Table 4).

Table 4 Comparison in weight of 7-18 years old $\mathrm{Li}$ and national girls $(\mathrm{kg})$

\begin{tabular}{cccccc}
\hline Subject & \multicolumn{5}{c}{ Average } \\
\cline { 2 - 5 } & 1985 & 2000 & 2005 & 2010 & 2014 \\
\hline Li nationality school girl & 35.35 & 36.05 & 35.63 & 35.72 & 38.16 \\
National rural school girl & 35.92 & 38.04 & 38.98 & 40.13 & \\
Difference & -0.57 & -1.99 & -3.35 & -4.41 & \\
\hline
\end{tabular}

Comparison of Changes of Chest in Different Periods of Li Nationality Students . From the Fig .3,the performance of Li nationality students is surprised to the people. From 1995 to 2010,In 20 years,the chest of Li nationality seems no much changes.and since 1995,the average level of chest is lower than in 1985. 


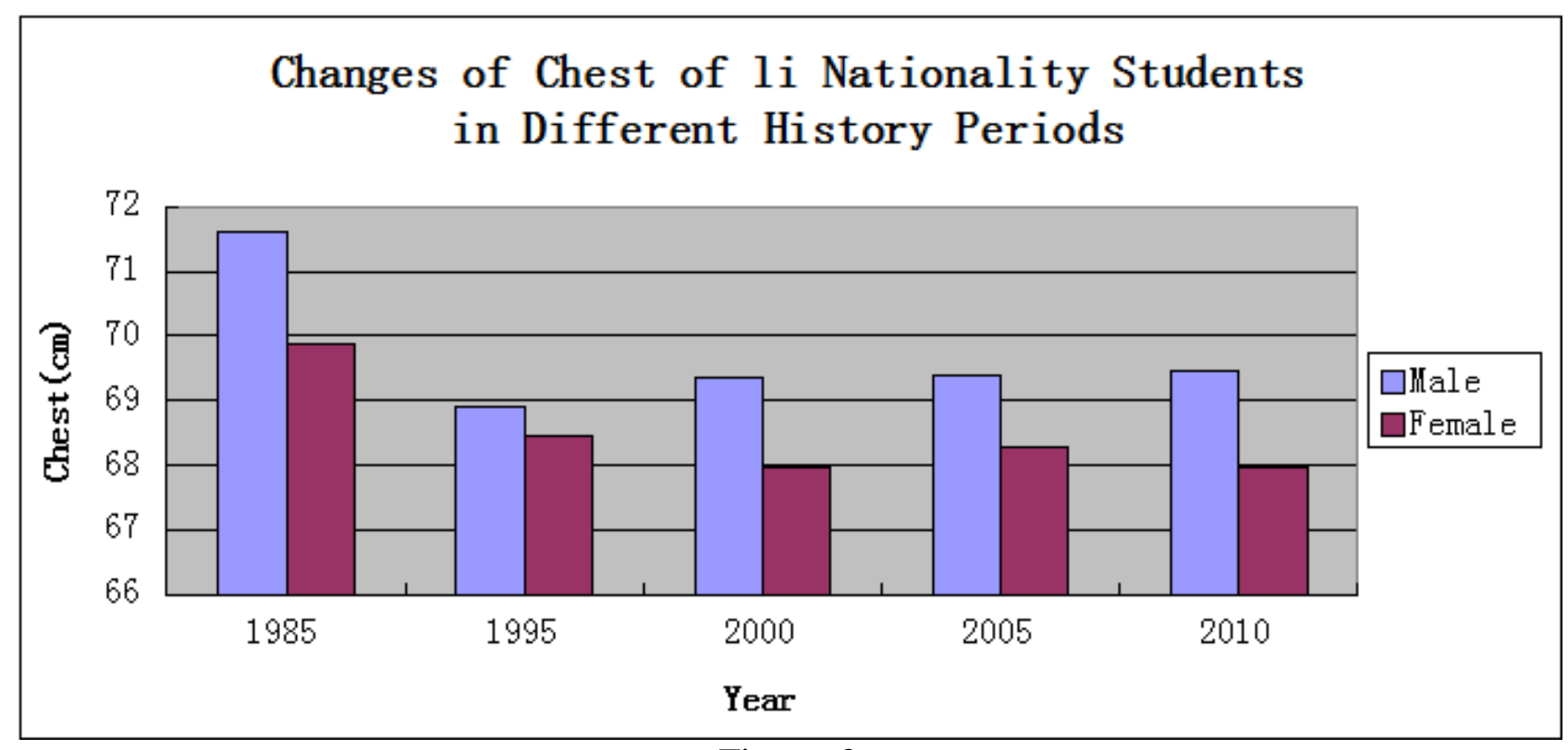

Figure. 3

Comparison in Chest of Li and Han Nationality Male Students. In the comparison of chest,from the table 5,the Li nationality is still lower than national students, and there has a gradually expanding gap between Li nationality school boys and national school rural school boys. The same viewpoint can be see from2011.[7]

Table 5 Comparison in chest of 7-18 years old Li and national boys $(\mathrm{cm})$

\begin{tabular}{cccccc}
\hline Subject & \multicolumn{5}{c}{ Average } \\
\cline { 2 - 5 } & 1985 & 1995 & 2000 & 2005 & 2010 \\
\hline Li nationality school boy & 71.62 & 68.91 & 69.35 & 69.39 & 69.46 \\
National rural school boy & 70.11 & 70.27 & 70.78 & 71.05 & 72.31 \\
Difference & 1.51 & -1.36 & -1.43 & -1.66 & -2.85 \\
\hline
\end{tabular}

Comparison in Chest of $\mathrm{Li}$ and Han Nationality Female Students. From the table 6,since 1995,Li nationality's chest is always lower than Han national rural school girls.

Table 6 Comparison in chest of 7-18 years old Li and national girls $\quad(\mathrm{cm})$

\begin{tabular}{cccccc}
\hline \multirow{2}{*}{ Subject } & \multicolumn{5}{c}{ Average } \\
\cline { 2 - 5 } & 1985 & 1995 & 2000 & 2005 & 2010 \\
\hline Li nationality school girl & 69.86 & 68.45 & 67.96 & 68.26 & 67.95 \\
National rural school girl & 68.68 & 68.83 & 69.54 & 69.69 & 70.63 \\
Difference & 1.18 & -0.38 & -1.58 & -1.43 & -2.68 \\
\hline
\end{tabular}

\section{Conclusion}

Li nationality students of Hainan province has a general rapid increase in body shape in China,except the chest.The same points can be see from2011.[7]

With a comparison of 30 years,Li nationality students of Hainan province is always lower in body shape than Han nationality national rural students,such as height,weight and chest,and the gap is growing. 
1995 is a pivotal point to Li nationality students' body shape ,it is a watershed of comparison.Since 1995,Li nationality students' average level is lower than national Han nationality's level.The same can be see from historical documents.[,9,10,11]

\section{Acknowledgements}

This work is supported by foundation of 2011 Research Project of Qiongtai Teachers College of China.

\section{References}

[1] W.T.Hao,Y.L.Zhang:Journal of Beijing Sport University.Vol.29(2006)No.11,p.1523-1524.(In Chinese)

[2]J.J.Sun,Y.Sheng:Journal of Guangxi Normal Univeristy For Nationalities.Vol.29(2012)No.4, p.148. (In Chinese)

[3] Research team:2010 Reports on the Physical Fitness and Health Research of Chinese School Students(Higher Education Press,China2012).(In Chinese)

[4] Research team:2005 Reports on the Physical Fitness and Health Research of Chinese School Students(Higher Education Press,China2007).(In Chinese)

[5] Research team:2000 Reports on the Physical Fitness and Health Research of Chinese School Students(Higher Education Press,China2002).(In Chinese)

[6] Research team:1995 Reports on the Physical Fitness and Health Research of Chinese School Students(Jilin science and Technology Press,China1996).(In Chinese)

[7] Research team:1985 Reports on the Physical Fitness and Health Research of Chinese School Students,(Higher Education Press,China1987).(In Chinese)

[8] W.H.He,J.C.Xu and J.X.Hu..Journal of Jining University.Vol.32(2011)No.3,p.96.(In Chinese)

[9] J.Y.Hong:Fujian Sports Science and Technology.Vol.24(2005)No.1,p.34.(In Chinese)

[10] Y.Wang,C.Z.Yuan and H.X.Zang:Journal of Physical Education.Vol.9(2002) No.5, p.121.(In Chinese)

[11] Y.Wang.Z.Y.Yang:Journal of Wuhan Institute of Physical Education.Vol.36(2002) No.2, p.51.(In Chinese) 